OPEN ACCESS

ISSN 2541-2841 (online)

ISSN 2302-6790 (print)

Edited by:

Sitti Murni Kaddi

Reviewed by:

Mochammad Syahri and Achmad

Herman

${ }^{*}$ Correspondence:

Cedric Louise Tanamas

cedriclouise03@gmail.com

Received: August 10, 2020

Accepted: August 13, 2020

Published: September 1, 2020

Citation:

Tanamas CL, Santosa NS and

Cristiani N (2020) Theater as a

Media to Introduce Papuan Culture

to Millennial Generation.

Kanal. 9:1.

doi: 10.21070/kanal.v9i1.794

\section{Theater as a Media to Introduce Papuan Culture to Millennial Generation}

\section{Teater Sebagai Media Untuk Memperkenalkan Budaya Papua Kepada Generasi Milenial}

\author{
Cedric Louise Tanamas ${ }^{1 \star}$, Natasia Surya Santosa ${ }^{2}$, Natasya Cristiani ${ }^{3}$ \\ ${ }^{1}$ Performing Arts Communication, Communication \& Business Institute LSPR Jakarta, Jakarta, Indoensia, ${ }^{2}$ Public Relation, \\ Communication \& Business Institute LSPR, Jakarta, Indonesia, ${ }^{3}$ Public Relation, Communication \& Bussiness Institue \\ LSPRR, Jakarta, Indonesia
}

Papua is often assumed and viewed as a primitive tribe and second-class society, but on the other hand Papua has a diverse, unique and beautiful culture that can be used as a national cultural heritage. Performing arts are an effective communication medium in conveying messages because they involve the audience and provide real experiences, one of which is theater performance art. Theater itself is an effective communication to introduce Papua culture to the millennial generation because in this case theater is very close and in demand by the millennial generation. Journal articles as a medium to introduce Papua culture to the millennial generation use one of the research methods it's literature studies. To support any required data, the author takes several journal article references that are related to the above this theme. In addition to these references, as an addition to secondary data, the authors conducted interviews and surveys to obtain supporting facts and data needed in this research process. Based on the methods and processes that have been carried out, it can be concluded that performances such as theater can be an effective medium to introduce Papua culture to the public, especially millennial generation.

Keywords: Papuan Culture, Theatre, Performing Arts, Performing Arts Communication, Millennial 


\section{PENDAHULUAN}

Tera (2016) menyatakan bahwa Papua adalah provinsi di Indonesia yang terletak di pulau Nugini bagian barat dan juga merupakan pulau yang berada di Indonesia Timur. Sebagian besar wilayahnya tertutupi oleh hutan lebat yang menjadi habitat hewan-hewan endemik Indonesia sepeti burung cenderawasih, tapir dan kasuari. Papua dibagi menjadi dua Provinsi, yaitu Papua dan Papua Barat. Papua telah dideklarasikan sebagai Provinsi Konservasi pada 19 Oktober 2015. Provinsi Konservasi merupakan upaya pemerintah untuk melindungi dan juga mengelola sumber daya alam (SDA) sebagai modal pembangunan yang akan meningkatkan kesejahteraan masyarakat Papua Barat (WWF, 2015). Menteri Pariwisata, Arief Yahya pada rapat Koordinasi Nasional Pariwisata ke IV 2017 menyampaikan bahwa Raja Ampat yang terletak di Papua Barat pun menjadi salah satu destinasi wisata unggulan Kementrian Pariwisata Indonesia (Adiakurnia, 2017).

Setiap kali membicarakan Papua, selalu ada kesenjangan antara apa yang diasumsikan dengan apa yang orang Papua rasakan. Hal ini dikarenakan informasi mengenai Papua masih gelap dan tidak pernah penuh karena ada batasan.hal ini membuat informasi tentang Papua merupakan hal yang paling bercela, terutama untuk orang di luar Papua (Thaniago, 2018). Widigi (2020) menuliskan bahwa sejak dahulu Papua dipandang sebagai orang yang terbelakang, primitif, tidak beradab dan menjadi orang kelas dua. Larasati (2014) menjelaskan tentang representasi etnis Papua dalam film "Lost in Papua" bahwa Papua direpresentasikan sebagai etnis yang primitif, etnis yang tidak terpisahkan dari alam dan digambarkan sebagai suku yang menyukai kekerasan yang dikaitkan dengan kanibalisme. Hal ini secara tidak langsung membentuk persepsi publik terhadap Papua.

Di sisi lain, Papua memiliki banyak keunikan, baik keadaan alam maupun kebudayaannya, dari rumah adat, pakaian adat, tari-tarian adat, lagu daerah dan juga Bahasa Papua. Papua juga memiliki ratusan suku yang berbeda Bahasa dan adat istiadatnya (Somantri, 2008). Staf ahli multikultur Republik Indonesia, Hary Kuncoro Drajat dalam (Siswanto, 2016) mengatakan bahwa di provinsi Papua memiliki banyak kebudayaan yang dapat menjadi warisan budaya dunia, salah satunya adalah noken. Noken telah dijadikan warisan budaya dunia pada tahun 2011, dan hal itu sudah menjadi kebanggaan bagi masyarakat Papua. Budaya Papua perlu terus dilestarikan karena masih banyak budaya yang ada di provinsi Papua yang dapat dijadikan warisan budaya dunia. Pelestarian budaya yang baik dapat meningkatkan pendapatan ekonomi masyarakat. Ada tiga hal yang perlu diperhatikan saat melakukan pelestarian budaya, yaitu perlindungan, pelestarian dan pemanfaatan.

Berdasarkan Statistik Kebudayaan 2017 oleh Kementrian Pendidikan dan Kebudayaan, Papua menduduki posisi keempat tertinggi sebagai provinsi yang memiliki warisan budaya non-benda setelah Jawa Timur, Jawa Barat dan Jawa Tengah. Kategori Warisan Budaya Tak Benda di Indonesia, terdiri dari
4 kategori, yaitu seni pertunjukan; adat istiadat masyarakat, ritual, dan perayaan-perayaan; pengetahuan dan kebiasaan perilaku mengenai alam dan semesta; dan kemahiran kerajinan tradisional (Lokadata, 2017). Deputi Bidang Pengembangan Pemasaran Pariwisata Nusantara (Deputi BP3N) Kementerian Pariwisata, Esthy Reko Astuti, mengatakan bahwa budaya mendapat porsi paling besar menjadi faktor keunggulan pariwisata di Indonesia dengan angka $60 \%$, diikutin oleh faktor keindahan alam sebesar $35 \%$ dan potensi buatan manusia sebesar 5\% (Viranda, 2017).

Banyak budaya Indonesia yang diklaim oleh negara asing, beberapa diantaranya, yaitu Tari Reog Ponorogo, Batik dan Tari Kuda Lumping. Hal ini dapat memicu kontroversi yang masalahnya tak ada pemecah, kecuali dengan adanya generasi muda yang mengenal dan melestarikan budaya Indonesia agar tidak diklaim oleh negara lain (Walker, 2019).

Fenomena seperti ini dapat dikatakan sebagai pengikisan budaya. Fenomena ini bila tidak diatasi dengan serius, dapat mengakibatkan Indonesia kehilangan identitasnya seiring berjalannya waktu. Karenanya, tujuan dari penulisan artikel ilmiah ini adalah mengkaji peran pertujunkan teater untuk melestarikan budaya Papua. Budaya merupakan salah satu harta warisan yang patut dilestarikan sebagai unsur pembentuk dari identitas nasional di Indonesia.

Supriyanto (2016) menyatakan bahwa tanpa disadari budaya di Indonesia terancam hilang seiring berjalannya waktu. Ada beberapa faktor yang menyebabkan budaya di Indonesia mulai menghilang. Faktor-faktor tersebut merupakan faktor internal dan juga eksternal. Faktor internal yang menyebabkan budaya Indonesia terancam hilang adalah rakyat Indonesia sendiri mengabaikan budaya Indonesia, terutama di kalangan remaja atau generasi muda. Faktor eksternal yang menjadi ancaman terhadap hilangnya kebudayaan Indonesia adalah pengaruh globalisasi, derasnya arus informasi yang masuk ke Indonesia mengakibatkan banyak budaya asing yang telah datang dan tumbuh di dalam Indonesia.

Mubah and Syafril (2011) menyatakan globalisasi merupakan sesuatu yang tidak dapat dicegah, namun globalisasi memiliki efek yang dapat mematikan budaya lokal, walau hal positif dari modernisasi dapat mendorong masyarakat pada kemajuan, kita tetap harus menyikapi globalisasi dengan bijaksana. Daya tahan budaya lokal dalam menghadapi serbuan budaya asing relatif lemah.Globalisasi memiiki 5 indikator, satu diantaranya adalah westernisasi. Westernisasi adalah pendifusian nilai-nilai budaya Barat ke dalam budaya lokal. Hal ini dimulai dari memudarnya budaya lokal dan kecenderungan budaya dunia yang menjadi homogen. Perlahan seiring berjalannya waktu, budaya lokal akan sepi peminatnya, dan masyarakat cenderung lebih tertarik budaya asing karena dianggap lebih modern. Menolak globalisasi bukanlah cara tepat, karena itu berarti menghambat kemajuan bangsa dari segi ilmu pengetahuan dan teknologi. Oleh karena itu dibutuhkan strategi untuk meningkatkan daya tahan budaya lokal dalam menghadapi terpaan budaya asing yang masuk.

Banyaknya budaya asing yang masuk, membuat kita 
memerlukan strategi yang perlu dilakukan untuk mempertahankan budaya lokal yaitu adanya kepedulian yang tinggi dari masyarakat, jika masyarakat peduli terhadap budaya lokal maka kebudayaan akan tetap terjaga dan lestari, namun kepedulian itu belum terlihat secara nyata, padahal ancaman sudah terlihat jelas. Strategi kedua adalah pemanfaatan teknologi informasi. Masuknya budaya asing ke Indonesia dan memperngaruhi budaya bangsa disebabkan oleh kemampuannya dalam memanfaatkan teknologi informasi. Di era ini, siapa yang menguasai teknologi informasi memiliki peluang lebih besar untuk dikenal dan menguasai dunia, dibandingkan dengan yang lemah. Oleh karena itu, Indonesia perlu untuk memanfaatkan akses kemajuan teknologi informasi dan komunikasi sebagai alat dalam upaya pelestarian budaya bangsa. Budaya lokal yang khas dan unik dapat menjadi nilai tambah dan daya tarik Indonesia di mata dunia, namun memerlukan media sebagai alat untuk memasarkan budaya lokal ke seluruh Indonesia dan dunia. Jika daya tarik Indonesia semakin tinggi maka akan berpengaruh terhadap dengan ekonomi dan investasi di Indonesia (Mubah and Syafril, 2011).

Strategi kreatif telah diperlihatkan dalam pertunjukan teater I La Galigo, pertunjukan teater yang mengangkat budaya Sulawesi. Pementasan I La Galigo sukses dan efektif sebagai sarana dalam menyampaikan nilai-nilai luhur budaya Indonesia, karena menggunakan komunikasi non-verbal memperkecil dalam meminimalisir miskomunikasi, karena kinestetis atau gerakan merupakan bahasa universal (Zulfikar, 2017).

\section{HASIL DAN PEMBAHASAN}

\section{Degradasi Budaya Papua}

Christine Sanggenafa, dosen antropologi di Universitas Cenderawasih, dalam wawancara yang dilakukan oleh peneliti pada 30 Juli 2020 melalui platform online mengatakan bahwa budaya Papua dikenal namun hanya budaya yang populer saja seperti Noken, koteka, rumah adat Honai yang sering dipublikasikan pada buku-buku pelajaran di sekolah. Namun budaya Papua masih banyak daripada itu, dan juga budaya Papua bisa bisa dikategorikan berdasarkan 2 letak geografis masyarakatnya, yaitu masyarakat pegunungan dan masyarakat pesisir. Hal ini membuat banyak budaya Papua yang belum dikenal oleh masyarakat.

Christine Sanggenafa menambahkan bahwa era globalisasi ini membuat generasi milenial menjadi lebih mencintai budaya asing atau hal-hal yang lagi tren. Hal ini tidak terjadi di luar Papua saja, namun milenial di Papua pun cenderung melakukan hal-hal yang "kekinian". Milenial di Papua banyak yang tidak mengenal budaya-budaya yang ada, mereka sekedar tau nama dari suatu upacara adat tanpa tau makna dibalik upacara tersebut, bahkan mereka dirumah pun jarang menggunakan bahasa asli mereka dan cenderung menggunakan bahasa Indonesia, karena merasa menggunakan bahasa asal itu kuno.

Banyaknya budaya asing yang masuk membuat kita memerlukan strategi yang perlu dilakukan untuk mempertahankan budaya lokal yaitu adanya kepedulian yang tinggi dari masyarakat, jika masyarakat peduli terhadap budaya lokal maka kebudayaan akan tetap terjaga dan lestari, namun kepedulian itu belum terlihat secara nyata, padahal ancaman sudah terlihat jelas. Strategi kedua adalah pemanfaatan teknologi informasi. Masuknya budaya asing ke Indonesia dan memperngaruhi budaya bangsa disebabkan oleh kemampuannya dalam memanfaatkan teknologi informasi. Di era ini, siapa yang menguasai teknologi informasi memiliki peluang lebih besar untuk dikenal dan menguasai dunia, dibandingkan dengan yang lemah. Oleh karena itu, Indonesia perlu untuk memanfaatkan akses kemajuan teknologi informasi dan komunikasi sebagai alat dalam upaya pelestarian budaya bangsa. Budaya lokal yang khas dan unik dapat menjadi nilai tambah dan daya tarik Indonesia di mata dunia, namun memerlukan media sebagai alat untuk memasarkan budaya lokal ke seluruh Indonesia dan dunia. Jika daya tarik Indonesia semakin tinggi maka akan berpengaruh terhadap dengan ekonomi dan investasi di Indonesia (Mubah and Syafril, 2011).

Generasi millennial atau generasi Y merupakan generasi yang terlahir pada tahun 1984-1999. IDN Research Institute mengkatergorikan generasi millennial menjadi 2, yaitu millennial senior (1984-1991) dan millennial junior (1992-1999). Bambang Brodjonegoro, Kepala Bappenas (Badan Perencanaan Pembangunan Nasional) periode 2016 - 2019 mengatakan bahwa komposisi penduduk Indonesia yang tergolong generasi millennial sebanyak 90 juta penduduk, dengan angka kelahiran 2,28 (per 1000 orang per tahun) (Sembiring, 2018).

Rasa cinta terhadap budaya bangsa sangat dibutuhkan tidak hanya di masa lampau, melainkan juga di masa kini dan yang harus dijaga dan dipelihara oleh setiap bangsa, terutama remaja atau generasi muda agar budaya tidak hilang di masa yang akan datang. Penjabaran diatasmendapat dukukungan dari hasil survey yang dilakukan oleh peneliti kepada 50 responden dengan kriteria kelahiran tahun 1984-1999 (generasi millennial) pada 1-2 April 2020 lalu, menunjukan bahwa $76 \%$ dari 50 responden menganggap budaya asing lebih menarik dari budaya Indonesia, dan $62 \%$ menyatakan bahwa mereka lebih mencintai budaya asing.

\section{Teater Sebagai Media Komunikasi}

Hasil survey yang dilaukan oleh peneliti secara daring menunjukan pengetahuan responden terhadap budaya Papua dengan angka 50\% mengetahui budaya potong jari, 24\% Ebai adalah rumah adat Papua, 36\% Festival Lembah Baliem, 40\% Ritual Sasi, 34\% Mansorandak, 38\% Tari Musyoh, 34\% Triton (alat musik tradisional) merupakan budaya Papua dan $74 \%$ responden menjawab bahwa Ma'nene' adalah budaya Papua, sedangkan sebenarnya Ma'nene' adalah budaya Toraja.

Selain itu, hanya $16 \%$ responden yang melakukan kegiatan yang bertujuan untuk melestarikan budaya Indonesia. Apabila hal ini terus terjadi, maka akan banyak banyak budaya lokal yang akan punah dan tidak lestari, sehingga memungkinkan 
untuk budaya kita diklaim oleh negara lain.

Hal yang menyebabkan turunnya minat generasi milenial terhadap budaya lokal dikarenakan adanya miskomunikasi antara komunitas teater budaya dengan penonton. Miskomunikasi terbentuk karena komunitas teater budaya kurang mampu untuk beradaptasi dalam mengikuti perkembangan jaman. Komunitas teater budaya cenderung tetap menggunakan bahasa asli dari budaya yang mereka angkat. Seperti contoh, ketika teater budaya mengangkat budaya Batak, mereka akan menggunakan bahasa Batak juga saat berlakon, sehingga membuat banyak penonton tidak dapat menerima pesan yang disampaikan oleh para aktor dengan baik. Hal ini dapat diatasi dengan cara menggunakan bahasa Indonesia saat berlakon, namun tetap komunitas teater harus berpegang dengan pakem-pakem budaya yang sedang dimainkan, baik dari segi musik, tata rias, tata busana, desain panggung dan juga aksen saat berbicara. Generasi milenial lebih meminati teater yang lebih memiliki sifat entertain, contohnya teater- teater broadway. Untuk menarik minat penonton, Teater Legiun menggunakan suatu cara yaitu, menggabungkan unsur budaya lokal dan modern dalam pertunjukan yang dibuat, seperti teater yang mengangkat budaya "Cina Peranakan" dari Semarang, tapi tidak menggunakan Bahasa Jawa, melainkan Bahasa Indonesia, tetapi unsur-unsur budaya dan "pakem-pakem" budaya itu sendiri tetap dijaga, dari segi kostum, instrumen musik, dan tata rias. Rini mengatakan bahwa seniman teater atau komunitas teater seharusnya memiliki pola pikir "We must adapt to survive", dimana seniman dapat mengikuti perkembangan zaman agar tetap bisa bertahan di era ini, agar tidak terjadi miscommunication dan setiap pesan yang ingin disampaikan dapat disampaikan dengan efektif tetapi tanpa mengurangi nilai-nilai budaya yang ingin disampaikan. Hal ini disampaikan oleh Rini dari Teater Legiun saat wawancara pada 26 Oktober 2018 lalu.

Teater berasal dari kata Yunani "theatron" yang memiliki arti tempat atau gedung pertunjukan. Semakin berkembangnya pengertian-pengertian tentang teater, dalam pengertian lebih luas kata teater diartikan sebagai hal-hal yang dipertunjukkan di depan orang banyak. Harymawan mengatakan bahwa "tidak ada teater tanpa aktor, baik berwujud riil manusia maupun boneka, terungkap di layar maupun pertunjukan langsung yang dihadiri penonton, serta laku di dalamnya merupakan realitas fiktif" Santosa et al. (2008). Dengan demikian dapat disimpulkan bahwa teater adalah suatu pertunjukan lakon yang dimainkan di tempat atau gedung pertunjukan dan disaksikan oleh penonton.

Komunikasi atau communication dalam bahasa Inggris berasal dari kata Latin communist yang memiliki arti "sama", communico, communication, atau communicare yang berarti "membuat sama" atau to make common. Komunikasi menyarankan bahwa suatu makna, suatu pikiran, atau suatu pesan dianut secara sama (Mulyana, 2007).

Everett M. Rogers,menjelaskan bahwa komunikasi merupakan proses dimana suatu gagasandisalurkan dari sumber kepada penerima (individu atau kelompok), dengan tujuan untuk mengubah tingkah laku mereka Cangara (2004).

Dalam Buku "Ilmu, Teori dan Filsafat Komunikasi", disebutkan empat fungsi komunikasi, yaitu untuk memberikan informasi (to inform), untuk mengedukasi (to educate), untuk menghibur (to entertain), dan untuk mempengaruhi (to influence). Effendy juga menyebutkan empat tujuan komunikasi, yaitu untuk mengubah sikap (to change the attitude), mengubah opini, pendapat atau pandangan (to change the opinion), mengubah perilaki (to change the behavior), dan mengubah masyarakat (to change the society) (Effendy, 2003).

Salah satu solusi dalam menyikapi fenomena terhadap hilangnya rasa cinta budaya pada generasi muda Indonesia tersebut dapat dilakukan dengan cara memperkenalkan dan memberikan edukasi melalui seni pertunjukan, yaitu teater. Teater adalah pertunjukan lakon yang dimainkan di atas pentas dan disaksikan oleh penonton (Santosa et al., 2008). Sebagai seni, teater merupakan gabungan dari berbagai bentuk seni. Jika dibandingkan dengan kesenian lainnya, teater memiliki kelebihan yang lebih spesifik. Berbeda dengan film, yang dapat disaksikan atau ditonton berulang kali dan pesan yang disampaikan akan sama. Teater memiliki cara dan kelebihan tersendiri dalam menyampaikan pesan kepada penonton, dimana sarana utama atau media utama dalam penyampaian pesan adalah tubuh sang aktor dan panngung menjadi tempat untuk menyampaikan pesan. Menonton teater secara langsung akan terasa berbeda, karena pada dasarnya teater adalah pertunjukan langsung, karena apabila menyaksikan pertunjukan teater yang telah direkam itu berarti ada beberapa esensi teater tersebut yang telah hilang. Sehingga, menyaksikan pertunjukan teater secara langsung akan membuat pesan yang disampaikan lebih efektif (Riantiarno, 2011).

Sumandiyo Hadidalam S dalam Saaduddin and Novalinda (2017) mengatakan bahwa komunikasi yang disampaikan melalui seni pertunjukan akan memberikan pengalaman berharga yang bermula dari imajinasi kreatif. Seni pertunjukan dapat dikatakan bermakna atau dapat diresapi bila di dalamnya memuat pesan komunikatif.

Pertunjukan teater dapat menjadi media yang efektif dalam menyampaikan pesan kepada generasi millennial karena berdasarkan hasil survey yang dilakukan oleh peneliti, 90\% responden dengan kriteria generasi millennial tertarik untuk menonton teater. Setiap pertunjukan menuntut adanya komunikasi yang baik antara pemain dan penonton. Komunikasi yang terbangun dengan baik antara pemain dengan penonton dapat menjadi salah satu tolak ukur suksesnya pementasan seni, dimana pementasan teater memiliki ideologi untuk memberikan pesan atau amanat kepada penoton setelag pertunjukan berakhir (Hidayat, 2010).

Komunikasi pemain dalam pertunjukan teater dengan penonton akan berjalan dengan baik ketika pemain dapat menguasai dan memahami tokoh dan dialognya secara menyeluruh. Pesan-pesan yang dapat tersampaikan kepada penonton dan juga dapat menyentuh perasaan penonton dapat menambah suksesnya sebuah pertunjukan. Dalam kisah "Romeo dan Juliet", William Shakespeare mengungkapkan perny- 
ataan "apalah arti sebuah nama”. Naskah ini mempengaruhi banyak kalangan di dunia, terutama anak-anak muda, bahkan orang yang tidak tahu-menahu tentang William Shakespeare sekalipun (Hidayat, 2010).

\section{KESIMPULAN}

Teater merupakan salah satu seni pertunjukan yang dapat dimanfaatkan untuk menyampaikan pesan. Teater dianggap media yang efektif dalam menyampaikan pesan karena melalui teater, penonton dapat terlibat secara langsung dan pesan akan tersampaikan melalui audio dan visual disertai pengalaman empiris. Generasi milenial memiliki minat yang tinggi terhadap pertunjukan teater, namun teater yang disajikan perlu disesuaikan dengan kebutuhan dan juga dengan cara-cara yang lebih kreatif dan menarik sehinggan generasi milenial dapat menikmati dan mengerti pesan yang disampaikan melalui pertunjukan teater tersebut. Generasi milenial lebih meminati teater yang bersifat menghibur dan tidak menyukai hal-hal yang mereka anggap kuno atau tidak up-to-date, hal ini dikarenakan adanya globalisasi media dan budaya yang tidak terhindarkan.Kebudayaan asli dari Papua sendiri memiliki banyak keunikan, baik keadaan alam maupun kebudayaannya, dari rumah adat, pakaian adat, tari-tarian adat, lagu daerah dan juga Bahasa Papua. Namun, seringkali budaya Papua diasumsikan sebagai etnis yang primitif, etnis yang tidak terpisahkan

\section{REFERENCES}

Adiakurnia, M. I. (2017). Ini 18 Destinasi Unggulan Indonesia yang Siap Dijual Tahun Depan. Kompas.com. https:/travel.kompas.com/read/2017/12/13/ 080300727/ini-18-destinasi-unggulan-indonesia-yang-siap-dijual-tahundepan. (Accessed on 2020-01-11).

Cangara, H. (2004). Pengantar Ilmu Komunikasi (Jakarta: PT. Raja Grafindo Persada).

Effendy, O. U. (2003). Ilmu Teori dan Filsafat Komunikasi (Bandung: PT. Citra Aditya Bakti).

Hidayat, A. (2010). Komunikasi Dalam Pertunjukan Drama: Antara Pengarang, Aktor, Dan Penonton. Komunika 4, 32-39.

Larasati, C. E. (2014). Representasi Identitas Etnis Papua Dalam Film Lost in Papua. Jurnal Unair Commonline Departemen Komunikasi 3, 488-497.

Lokadata (2017). Jumlah Warisan Budaya Tak Benda di masing-masing provinsi. Lokadata.com. https://lokadata.beritagar.id/chart/preview/jumlah-warisanbudaya-tak-benda-di-masing-masing-provinsi-1519791925. (Accessed on 2020-01-13).

Mubah, A. and Syafril (2011). Strategi Meningkatkan Daya Tahan Budaya Lokal dalam Menghadapi Arus Globalisasi. Jurnal Unair 24, 302-308.

Mulyana, D. (2007). Ilmu Komunikasi Suatu Pengantar (Bandung: PT. Remaja Rosdakarya).

Riantiarno, N. (2011). Kitab Teater (Jakarta: Grasindo).

Saaduddin, S. and Novalinda, S. (2017). PERTUNJUKAN TEATER EKSPERIMENTAL HUHH HAHH HIHH: SEBUAH KOLABORASI TEATER TARI. Ekspresi Seni 19, 39-57. doi: 10.26887/ekse.v19i1.128.

Santosa, E., Subagiyo, H., Mardianto, H., Arizona, N., and Sulistiyo, N. H. (2008). Seni Teater. vol. 1 (Jakarta: Direktorat Pembinaan Sekolah Menengah Kejuruan, Departemen Pendidikan Nasional).

Sembiring, L. J. (2018). Bappenas: Jumlah Milenial di Indonesia Capai 90 Juta Orang. iNews.com. https://www.inews.id/finance/makro/bappenas-jumlahmilenial-di-indonesia-capai-90-juta-orang. (Accessed on 2019-07-22). dari alam dan digambarkan sebagai suku yang menyukai kekerasan yang dikaitkan dengan kanibalisme. Sehingga hal tersebut membentuk persepsi publik tentang betapa buruknya budaya Papua. Teater dapat menjadi sarana yang efektif untuk memperkenalkan budaya Papua, karena melalui teater, pesan akan tersampaikan melalui dialog, gerak, dan pengalaman kepada penonton. Namun, pertunjukan yang dilaksanakan perlu dibuat dengan cara-cara yang kreatif dan juga menarik tanpa menghilangkan nilai budaya yang ingin diperkenalkan sehingga persepsi publik tentang budaya Papua dapat berubah ke arah yang lebih baik. Selain itu, harapan lainnya adalah publik serta generasi milenial dapat melestarikan kebudayaan Papua.

\section{UCAPAN TERIMA KASIH}

Pada kesempatan kali ini, kami ingin mengucapkan segenap terima kasih kepada banyak pihak karena telah membantu serta mendukung sehingga artikel jurnal komunikasi ini dapat terselesaikan dengan baik. Kami ingin mengucapkan terima kasih terutama kepada yang terhormat Ibu Prita Kemal Gani, MBA, MCIPR, APR, (UK)., selaku Ketua Institut Komunikasi dan BisnisLSPR Jakarta, Ibu Olivia Deliani Hutagaol, M.Si, yang membimbing kami dalam proses penulisan artikel jurnal. Dr. Joe Harrianto Setiawan, Dosen Seminar of Research Proposal.

Siswanto, E. (2016). Berpotensi Jadi Warisan Dunia, Kebudayaan Papua Harus Dilestarikan. OkeNews.com. https://news.okezone.com/read/2016/06/ 20/340/1420597/berpotensi-jadi-warisan-dunia-kebudayaan-papua-harusdilestarikan. (Accessed on 2020-01-13).

Somantri, L. (2008). Mengenal Suku Bangsa Di Pegunungan Tengah Papua. Ejournal UPI, 1-14.

Supriyanto, M. A. (2016). Budaya Indonesia Menghilang Seiring Waktu. TribunNews.com. http://www.tribunnews.com/tribunners/2016/05/15/budayaindonesia-menghilang-seiring-waktu. (Accessed on 2020-01-12).

Tera, H. (2016). Kebudayaan Papua Yang Fenomenal. https://ilmuseni.com/senibudaya/kebudayaan-papua. (Accessed on 2020-03-03).

Thaniago, R. (2018). Mengapa Kita Selalu Salah Memahami Papua? Remotivi.com. http://www.remotivi.or.id/amatan/445/Mengapa-Kita-Selalu-SalahMemahami-Papua. (Accessed on 2019-02-21).

Viranda, L. (2017). Potensi Budaya Penyumbang Terbesar Sektor Pariwisata. Kompas.com. https://ravel.kompas.com/read/2017/07/11/190300027/potensi. budaya.penyumbang.terbesar.sektor.pariwisata. (Accessed on 2020-01-22).

Walker, S. (2019). Kebudayaan Indonesia Yang Diklaim Oleh Negara Asing. https: //www.sawalwalker.com/budaya-indonesia-diklaim-negara-asing. (Accessed on 2020-04-23).

Widigi, I. (2020). Sebaik Apapun Kau Menjadi Indonesia, Kau Tetap Papua. Suara Papua.com. https://suarapapua.com/2020/01/05/sebaik-apapun-kau-menjadiindonesia-kau-tetap-papua/. (Accessed on 2020-06-28).

WWF (2015). Deklarasi Papua Barat Sebagai Provinsi Konservasi. https:// www.wwf.or.id/?42763/Deklarasi-Papua-Barat-sebagai-Provinsi-Konservasi. (Accessed on 2020-01-11).

Zulfikar, A. (2017). Pementasan Teater I La Galigo Sebagai Sarana Komunikasi Nilai-Nilai Luhur Budaya Indonesia Di Kancah Internasional, 1-11. doi: https: //doi.org/10.31227/osf.io/n3ue.

Conflict of Interest Statement: The authors declare that the research was conducted in the absence of any commercial or financial relationships that could be construed as a potential conflict of interest. 
Copyright $\odot 2020$ Tanamas, Santosa and Cristiani. This is an open-access article distributed under the terms of the Creative Commons Attribution License (CC BY). The use, distribution or reproduction in other forums is permitted, provided the original author(s) and the copyright owner(s) are credited and that the original publication in this journal is cited, in accordance with accepted academic practice. No use, distribution or reproduction is permitted which does not comply with these terms. 